\title{
INOCULAÇÃO DE SEMENTES COM Azospirillum brasilense E DOSES DE NITROGÊNIO MINERAL EM MILHO CULTIVADO EM SISTEMA PLANTIO DIRETO
}

\author{
GABRIELA THOMAZINI ${ }^{1}$, MARIANA PANDOLFI REICHEMBACK ${ }^{1,}$ ORIVALDO ARF ${ }^{2}$, \\ GUSTAVO ANTONIO XAVIER GERLACH ${ }^{1}$, SALATIER BUZETTI ${ }^{2}$ \\ e RICARDO ANTONIO FERREIRA RODRIGUES ${ }^{2}$
}

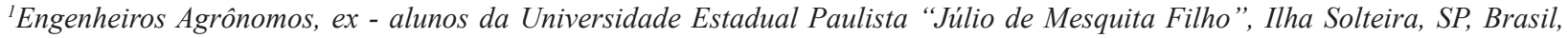
gabi_thomazini@yahoo.com.br,marianapr.agro@gmail.com,gustavao.gerlach@unesp.br

${ }^{2}$ Professores da Universidade Estadual Paulista"Júlio de Mesquita Filho", Ilha Solteira, SP, Brasil,

arf@agr.feis.unesp.br, salatier.buzetti@unesp.br,ricardo.rodrigues@unesp.br
\end{abstract}

Revista Brasileira de Milho e Sorgo, v.18, n.3, p. 396-407, 2019

\begin{abstract}
RESUMO - A procura de alternativas viáveis para reduzir o uso de fertilizantes tem crescido e a inoculação de sementes com Azospirillum brasilense pode suprir tal necessidade. Dessa forma o objetivo do trabalho foi avaliar o desempenho agronômico do milho, em função da inoculação das sementes com $A$. brasilense e das doses de nitrogênio em cobertura, em sistema plantio direto, nos anos agrícolas de 2010/11 e 2011/12 (primeira safra). Os experimentos foram conduzidos na área experimental da Faculdade de Engenharia de Ilha Solteira, localizada no município de Selvíria - MS, em LATOSSOLO VERMELHO Distrófico típico argiloso e com irrigação por aspersão. O delineamento experimental foi o de blocos casualizados dispostos em um esquema fatorial $5 \times 2$, com quatro repetições. Os tratamentos foram constituídos por cinco doses de nitrogênio em cobertura $\left(0,30,60,90\right.$ e $\left.120 \mathrm{~kg} \mathrm{ha}^{-1} \mathrm{de} \mathrm{N}\right)$, com ou sem inoculação de sementes com Azospirillum brasilense. Foram avaliados: população final de plantas, teor de $\mathrm{N}$ nas folhas, altura de plantas, altura de inserção da espiga, massa total da espiga despalhada, massa de grãos por espiga, massa de 100 grãos e produtividade de grãos. Os dados obtidos foram submetidos ao teste F da análise de variância, em seguida, por regressão polinomial para o estudo das doses de nitrogênio, ajustando-se modelos de equações lineares e quadráticas. Concluiu-se que a inoculação de sementes de milho com Azospirillum brasilense proporcionou maior população final de plantas, massa total de espiga despalhada, massa de grãos por espiga e produtividade de grãos; o incremento das doses de nitrogênio aplicado em cobertura aumentou o teor de $\mathrm{N}$ foliar, a massa de 100 grãos e a produtividade de grãos; a inoculação com Azospirillum brasilense e a dose $120 \mathrm{~kg} \mathrm{ha}^{-1}$ de nitrogênio proporcionou a maior produtividade de grãos.
\end{abstract}

Palavras-chave: Zea mays L.; Ureia. Irrigação por aspersão. Bactérias diazotróficas.

\section{SEED INOCULATION WITH Azospirillum brasilense AND MINERAL NITROGEN DOSES IN CORN CULTIVATED IN NO TILL SYSTEM}

\begin{abstract}
The search for viable alternatives to reduce the use of fertilizers has increased, and the inoculation of seeds with Azospirillum brasilense can supply this need. Thus, the objective of this work was to evaluate the agronomic performance of corn, as a function of seed inoculation with $A$. brasilense and sidedressing nitrogen rates, in no till System (SPD), in 2010/11 and 2011 / 12. The experiment was conducted at Experimental area of the Faculty of Engineering of Ilha Solteira, located in Selvíria county - MS, in a clayey distrophic haplustox with sprinkler irrigation. The experimental design was the randomized blocks arranged in a $5 \times 2$ factorial scheme, with four replications. The treatments consisted of five nitrogen doses $\left(0,30,60,90\right.$ and $120 \mathrm{~kg} \mathrm{ha}^{-1}$ of $\left.\mathrm{N}\right)$, with or without inoculation of seeds with Azospirillum brasilense. The final plant population, leaf $\mathrm{N}$ content, plant height, spike insertion height, total spike mass, grain mass per spike, mass of 100 grains and grain yield were evaluated. The obtained data were submitted to the variance analysis $\mathrm{F}$ test, then by polynomial regression for the study of nitrogen doses, adjusting models of linear and quadratic equations. It was concluded that the inoculation with $A$. brasilense presented a response in the corn crop for the following variables: final plant population, total spike mass, grain mass per spike and productivity, and the increase of the nitrogen dose for: $\mathrm{N}$ foliar, total mass of spike without straw, grain mass per spike, mass of 100 grains and productivity; the treatment with higher grain yield was obtained with inoculation and $120 \mathrm{~kg} \mathrm{ha}^{-1}$ of nitrogen.

Keywords: Zea mays L. Urea. Sprinkler irrigation. Diazotrophic bacteria
\end{abstract}


O milho é um cereal de grande importância para o agronegócio mundial, por ser considerado um dos principais insumos na produção de ração animal. Além disso, atualmente, sua produção vem aumentando, para ser utilizado também como matéria-prima na produção de etanol.

Dentre as tecnologias que visam o aproveitamento dos recursos naturais para o manejo eficiente do nitrogênio, destaca-se a fixação deste por microrganismos como o Azospirillum brasilense. Em gramíneas, a fixação de nitrogênio já vem sendo utilizada pelos produtores e a pesquisa avança para aprimoramento das técnicas de inoculação das bactérias diazotróficas.

Nos últimos anos, esta cultura ganhou destaque no cenário agrícola brasileiro devido principalmente ao aumento da produtividade e volume de grãos produzidos. A área ocupada com a cultura na primeira e segunda safra foi de 16,65 milhões de hectares na safra 2018/19. Em relação à produtividade de grãos, a média das duas épocas de cultivo foi de $5.476 \mathrm{~kg} \mathrm{ha}^{-1}$ e a produção total de 91,19 milhões de toneladas. Os principais fatores que contribuiram para o aumento da produtividade do milho destacam-se o clima e uso de tecnologia no manejo da cultura (Conab, 2019).

Graças à grande diversidade de cultivares, o milho pode ser produzido em todas as regiões do Brasil, com potencial de produtividades superiores a 12 $\mathrm{Mg} \mathrm{ha}^{-1}$ (200 sacas ha ${ }^{-1}$ ), não sendo raros aqueles que produzem mais do que $14 \mathrm{Mg} \mathrm{ha}^{-1}$. Contudo, as produtividades médias obtidas nessas regiões são bem inferiores, pois há grande diferença entre os sistemas de produção em uso e o potencial de produtividade (Cruz, 2012).

O milho é uma das plantas que mais se adéquam ao sistema plantio direto, pois está entre as gramíneas mais importantes para o cultivo comercial na safra de verão e fornece expressiva quantidade de palha e matéria orgânica ao sistema (Silva et al., 2009). A utilização desta como cobertura vegetal se encaixa perfeitamente no manejo sustentável, pois contribui para a melhoria das condições físicas, químicas e biológicas do solo, conforme comprovam Weber e Mielniczuk (2009).

Com a adoção de práticas conservacionistas, recuperação de áreas degradadas e intensificação da agricultura, haverá um incremento substancial no uso de fertilizantes no Brasil. No entanto, o mercado brasileiro de fertilizantes tem grande dependência das importações (MAPA, 2012).

Devido aos preços dos insumos terem aumentando, o custo de produção do milho se elevou, reduzindo a margem de lucro do produtor. Pelo fato do nitrogênio ser o elemento absorvido em maior quantidade pela cultura e por ser o que mais onera o custo de produção, há necessidade de pesquisas tendo em vista o seu melhor uso e eficiência. Essa necessidade existe devido à maior parte do nitrogênio do solo se encontrar em combinações orgânicas, sendo essa forma indisponível para os vegetais (Malavolta, 2006).

Uma das alternativas para diminuir os gastos com fertilizantes nitrogenados seria utilizar microrganismos que possam fazer a fixação biológica de nitrogênio atmosférico, suplementando, ou até mesmo, substituindo a utilização destes fertilizantes (Bergamaschi, 2006). Várias bactérias diazotróficas foram isoladas da cultura de milho, destacando se as espécies Azospirillum lipoferum, A. brasilense e Herbaspirillum seropedicae (Reis et al., 2000). Entre tais espécies, destacam-se as do gênero Azospirillum, que podem colonizar as raízes e o colmo da planta, sem causar sintomas de doença.

Segundo Bashan \& De-Bashan, 2010, a inoculação de milho com Azospirillum têm demonstrado 
grande potencial, apesar de o efeito positivo estar mais relacionado à produção de fitormônios do que a fixação biológica de nitrogênio (FBN). O trabalho foi desenvolvido com o objetivo de avaliar as características agronômicas e a produtividade do milho em função das doses de nitrogênio em cobertura e da inoculação de sementes com Azospirillum brasilense no sistema plantio direto em região de cerrado com irrigação por aspersão.

\section{Material e Métodos}

O experimento foi conduzido nos anos agrícolas de 2010/11 e 2011/12, em área experimental pertencente à Faculdade de Engenharia - UNESP, Campus de Ilha Solteira, localizada no município de Selvíria (MS), apresentando coordenadas geográficas $51^{\circ} 22^{\prime}$ de longitude Oeste de Greenwish e $20^{\circ} 22^{\prime}$ de latitude Sul, com altitude de 335 metros. O solo foi classificado como LATOSSOLO VERMELHO Distrófico típico argiloso (Santos et al., 2013). O clima da região, segundo classificação de Köppen, é do tipo Aw, com médias anuais de precipitação e temperatura são de $1370 \mathrm{~mm}$ e $23,5^{\circ} \mathrm{C}$, respectivamente, e a umidade relativa do ar está entre 70 e $80 \%$ (média anual) (Centurion, 1982).

Antes da instalação dos experimentos, em cada ano de cultivo, foram coletadas amostras de solo, sendo suas características químicas determinadas segundo a metodologia descrita por Raij (2001) (Tabela 1).
A área foi manejada em sistema plantio direto por mais de cinco anos, sendo que o milho foi semeado em sucessão à cultura do milheto nos dois anos de cultivo.

O delineamento experimental foi o de blocos casualizados dispostos em um esquema fatorial 5 x 2, com quatro repetições. Os tratamentos foram constituídos por cinco doses de nitrogênio em cobertura $\left(0,30,60,90\right.$ e $120 \mathrm{~kg} \mathrm{ha}^{-1}$ de $\left.\mathrm{N}\right)$, com ou sem inoculação de sementes com $A$. brasilense. As parcelas foram constituídas por 4 linhas de $5 \mathrm{~m}$ de comprimento no ano 2010/11 e por 10 linhas de $3 \mathrm{~m}$ de comprimento no ano 2011/12 e com espaçamento de $0,85 \mathrm{~m}$.

A adubação na semeadura foi realizada considerando a análise de solo e a recomendação para a cultura, utilizando-se $300 \mathrm{~kg} \mathrm{ha}^{-1}$ da fórmula 08-2816 e $300 \mathrm{~kg} \mathrm{ha}^{-1}$ da fórmula N-P-K 04-30-10, no primeiro e no segundo ano, respectivamente.

As semeaduras foram realizadas mecanicamente com o solo úmido nos dias 11 de novembro de 2010, e 3 de novembro de 2011, utilizando-se o híbrido AG 8088 PRO, nos dois anos com densidade de semeadura de 5,4 sementes $\mathrm{m}^{-1}$. Utilizou-se semeadora equipada com disco duplo em 2010 e com haste escarificadora em 2011. O AG 8088 PRO é um híbrido precoce, de alta produtividade, tolerante a doenças foliares e apresenta resistência as três principais lagartas que atacam o milho (broca do colmo, lagarta do cartucho e lagarta da espiga).

Tabela 1. Atributos químicos do solo na área experimental, na profundidade 0 - 0,20m. Selvíria (MS), Brasil.

\begin{tabular}{|c|c|c|c|c|c|c|c|c|c|}
\hline \multirow{2}{*}{ Ano } & \multirow{2}{*}{$\begin{array}{l}P \text { resina } \\
\mathrm{mg} \mathrm{dm}^{-3}\end{array}$} & \multirow{2}{*}{$\begin{array}{l}\text { M.O. } \\
\mathrm{g} \mathrm{dm}^{-3}\end{array}$} & \multirow{2}{*}{$\begin{array}{c}\mathrm{pH} \\
\mathrm{CaCl}_{2}\end{array}$} & $\mathbf{K}$ & $\mathrm{Ca}$ & Mg & $\mathbf{H}+\mathbf{A l}$ & CTC & \multirow{2}{*}{$\begin{array}{c}\mathrm{V} \\
(\%)\end{array}$} \\
\hline & & & & \multicolumn{5}{|c|}{$\mathrm{mmol}_{\mathrm{c}} \mathrm{dm}^{-3}$} & \\
\hline $2010 / 11$ & 22 & 20 & 5,0 & 3,2 & 27,0 & 15,0 & 47,0 & 93,0 & 49 \\
\hline $2011 / 12$ & 12 & 15 & 5,1 & 2,6 & 26,0 & 13,0 & 16,0 & 58,0 & 73 \\
\hline
\end{tabular}

Fonte: Laboratório de Fertilidade do Solo da FEIS - UNESP. 
Pouco antes da semeadura do milho, foi realizada a inoculação de sementes com $A$. brasilense para as parcelas inoculadas. O tratamento de sementes utilizado foi realizado com inseticida fipronil (50 g i.a $100 \mathrm{~kg}^{-1} \mathrm{sem}$ ), antes da inoculação. A inoculação foi realizada à sombra, utilizando-se a dose de $200 \mathrm{ml}$ de inoculante líquido para cada $25 \mathrm{~kg}$ de sementes no ano 2010/11 e $200 \mathrm{~g}$ de inoculante turfoso para $25 \mathrm{~kg}$ de sementes no ano 2011/12. Em ambos os anos a inoculação foi realizada com as estirpes $\mathrm{AbV}_{5}$ e $\mathrm{AbV}_{6}$, sendo que nos inoculantes utilizados haviam $2 \times 10^{8}$ células viáveis por grama do produto comercial. A adubação de cobertura com nitrogênio foi feita entre as fases $V_{5}$ e $\mathrm{V}_{6}$ do milho em filetes ao lado de cima das linhas de cultivo com Ureia como fonte de nitrogênio. $\mathrm{O}$ fornecimento de água, quando necessário, foi realizado por meio da irrigação por aspersão utilizando o equipamento pivô central, considerando que na região de cultivo tem ocorrido com frequência períodos de estiagens.

Foram realizadas as seguintes avaliações:

-População Final de Plantas: realizada pouco antes da colheita e foi obtida pela contagem das plantas de 2 linhas de $5 \mathrm{~m}$, no primeiro ano e 3 linhas de $3 \mathrm{~m}$ no segundo ano de cultivo, considerando-se inclusive as plantas acamadas e/ou quebradas, interpolando para plantas ha-1.

-Teor de N nas Folhas: foram coletadas 20 folhas opostas a base da espiga por parcela, no período de pleno florescimento, utilizando somente o terço médio de cada folha. Em seguida as folhas foram levadas para secar em estufa com circulação forçada de ar, com temperatura variando de 65 a $70^{\circ} \mathrm{C}$ e processadas em moinho tipo Wiley. Posteriormente foi realizada a determinação de $\mathrm{N}$, conforme metodologia proposta por Malavolta (1997).
-Altura de planta: foi determinada pouco antes da colheita em cinco plantas ao acaso, na área útil de cada parcela, a mensuração da distância média, em metros, do colo até a extremidade da parte aérea (folha bandeira).

-Altura de inserção de espiga: obtida nas mesmas plantas nas quais foi determinada a altura de plantas (5 plantas por parcela). Foi mensurada a distância média, em metros, do colo até a inserção da espiga.

-Massa total da espiga despalhada: foi determinada pela média da pesagem das espigas despalhadas de quinze plantas e corrigidas para umidade de $13 \%$.

-Massa de grãos por espiga: foi obtida a partir da pesagem dos grãos das espigas de quinze plantas, com teor de água dos grãos corrigido para 13\%, e realizando-se a média.

-Massa de 100 grãos: foi determinada pela avaliação deuma amostra de 100 grãos porparcela, tendo sua massa devidamente corrigida para a base úmida de $13 \%$.

-Produtividade de grãos: obtida a partir da colheita e trilha das espigas provenientes das linhas centrais das parcelas, sendo o peso de grãos ajustado para $13 \%$ de umidade, estimando-se a produtividade em $k g \mathrm{ha}^{-1}$

-Analise Estatística: os dados obtidos foram submetidos ao teste $\mathrm{F}$ da análise de variância, em seguida, por regressão polinomial para o estudo das doses de nitrogênio, ajustando-se modelos de equações lineares e quadráticas significativas pelo teste $\mathrm{F}$ $(p<0,01$ e $p<0,05)$. As análises estatísticas foram realizadas com o auxílio do software SISVAR desenvolvido por Ferreira (2011).

\section{Resultados e Discussão}

Não ocorreram diferenças significativas na altura de plantas e inserção de espiga, em ambos 
os anos, para inoculação (Tabela 2), assim como não houve ajuste às funções testadas para doses de nitrogênio. Silva et al. (2016), estudando a inoculação de sementes de milho com Azospirillum brasilense e aplicação de nitrogênio em cobertura em Montividiu - GO, constataram que a altura de plantas não foi influenciada pela inoculação e pelas doses de N. Porem, Basi (2013), avaliando a associação de $A$. brasilense e de nitrogênio em cobertura na cultura do milho em Guarapuava - PR, concluiu que a altura de planta foi influenciada pelo uso de A. brasilense e das doses de nitrogênio, o que não ocorreu com a altura de inserção de espiga. Segundo SANGOI et al., 2001, estas características, normalmente, estão relacionadas às características morfológicas, fisiológicas e fenológicas inerentes a cada genótipo, como o cultivar utilizado é de alta tecnologia e como os atributos do solo estavam com teores de médio a alto as plantas se desenvolveram uniformemente, o que explica a não diferença entre os tratamentos.

Quanto ao teor de $\mathrm{N}$ foliar, houve ajuste $(\mathrm{p}<0,01)$ no primeiro ano $(2010 / 11)$ para doses de nitrogênio, sendo observado efeito linear crescente $(\mathrm{y}$

Tabela 2. Valores médios de altura de planta e de inserção de espiga, teor de $\mathrm{N}$ foliar e população final de plantas, obtidos em milho inoculado com Azospirillum brasilense e doses nitrogênio em cobertura. Selvíria (MS), 2010/11 e 2011/12.

\begin{tabular}{|c|c|c|c|c|c|c|c|c|}
\hline \multirow[t]{2}{*}{ Tratamentos } & \multicolumn{2}{|c|}{$\begin{array}{l}\text { Altura de planta } \\
(\mathrm{m})\end{array}$} & \multicolumn{2}{|c|}{$\begin{array}{c}\text { Altura de inserção } \\
\text { de espiga }(\mathrm{m})\end{array}$} & \multicolumn{2}{|c|}{$\begin{array}{l}\text { Teor de } \mathrm{N} \text { foliar } \\
\qquad\left(\mathrm{g} \mathrm{kg}^{-1}\right)\end{array}$} & \multicolumn{2}{|c|}{$\begin{array}{c}\text { População final de } \\
\text { plantas (ha) }\end{array}$} \\
\hline & $2010 / 11$ & $2011 / 12$ & $2010 / 11$ & $2011 / 12$ & $2010 / 11$ & $2011 / 12$ & $2010 / 11$ & $2011 / 12$ \\
\hline \multicolumn{9}{|l|}{ Doses } \\
\hline 0 & 2,28 & 2,28 & 1,25 & 1,24 & $15,64^{1}$ & 12,42 & 63485 & 50005 \\
\hline 30 & 2,31 & 2,30 & 1,45 & 1,28 & 15,91 & 19,55 & 68057 & 49025 \\
\hline 60 & 2,33 & 2,30 & 1,32 & 1,25 & 17,81 & 15,31 & 67762 & 49021 \\
\hline 90 & 2,39 & 2,29 & 1,32 & 1,24 & 18,61 & 15,13 & 63632 & 51476 \\
\hline 120 & 2,33 & 2,30 & 1,31 & 1,26 & 19,31 & 18,47 & 58322 & 51721 \\
\hline \multicolumn{9}{|l|}{ Inoculação } \\
\hline Com & 2,31 & 2,30 & 1,35 & 1,25 & 17,83 & 17,25 & $68500 \mathrm{a}$ & $52043 \mathrm{a}$ \\
\hline Sem & 2,34 & 2,29 & 1,31 & 1,26 & 17,08 & 15,10 & $60004 \mathrm{~b}$ & $48456 \mathrm{~b}$ \\
\hline \multicolumn{9}{|c|}{$\operatorname{Pr}>F$} \\
\hline Inoculação (I) & 0,280 & 0,549 & 0,374 & 0,720 & 0,190 & 0,345 & $\mathrm{p}<0,01$ & 0,059 \\
\hline Doses (D) & 0,280 & 0,962 & 0,178 & 0,562 & $\mathrm{p}<0,01$ & 0,294 & 0,131 & 0,801 \\
\hline $\mathrm{I} \times \mathrm{D}$ & 0,911 & 0,634 & 0,656 & 0,269 & 0,861 & 0,762 & 0,231 & 0,389 \\
\hline C.V. $(\%)$ & 4,08 & 2,38 & 12,07 & 4,16 & 10,10 & 13,70 & 9,53 & 11,44 \\
\hline
\end{tabular}

C.V. $=$ coeficiente de variação. Médias seguidas pela mesma letra minúscula, na coluna, não diferem entre si (Teste $\mathrm{F}, \mathrm{P}>0,05) ;{ }^{1} \mathrm{y}=$ $15,4434+0,0335 x\left(R^{2}=0,95\right)$. 
Tabela 3. Valores médios de massa total de espiga despalhada e de grãos por espiga, massa de 100 grãos e produtividade, obtidos em milho inoculado com Azospirillum brasilense e doses nitrogênio em cobertura. Selvíria (MS), 2010/11 e 2011/12.

\begin{tabular}{ccccccccc}
\hline \hline \multirow{2}{*}{ Tratamentos } & \multicolumn{2}{c}{$\begin{array}{c}\text { Massa total de } \\
\text { espiga }(\mathrm{g})\end{array}$} & \multicolumn{2}{c}{$\begin{array}{c}\text { Massa de grãos por } \\
\text { espiga }(\mathrm{g})\end{array}$} & $\begin{array}{c}\text { Massa de } 100 \text { grãos } \\
(\mathrm{g})\end{array}$ & \multicolumn{2}{c}{$\begin{array}{c}\text { Produtividade } \\
\left(\mathrm{kg} \mathrm{ha}^{-1}\right)\end{array}$} \\
\cline { 2 - 9 } & $2010 / 11$ & $2011 / 12$ & $2010 / 11$ & $2011 / 12$ & $2010 / 11$ & $2011 / 12$ & $2010 / 11$ & $2011 / 12$ \\
\hline Doses & & & & & & & & \\
0 & 141 & $179^{1}$ & 121 & $158^{2}$ & 27,65 & $28,46^{3}$ & $5.151^{4}$ & $6.610^{5}$ \\
30 & 132 & 189 & 114 & 167 & 27,70 & 29,38 & 5.565 & 7.902 \\
60 & 152 & 210 & 130 & 186 & 28,14 & 30,06 & 6.192 & 7.854 \\
90 & 153 & 224 & 132 & 192 & 29,20 & 30,66 & 6.809 & 9.201 \\
120 & 163 & 220 & 140 & 194 & 28,51 & 30,17 & 6.161 & 8.983 \\
Inoculação & & & & & & & & \\
Com & $160 \mathrm{a}$ & 201 & $132 \mathrm{a}$ & 186 & 28,28 & 30,06 & 6.212 & $8.415 \mathrm{a}$ \\
Sem & $135 \mathrm{~b}$ & 202 & $111 \mathrm{~b}$ & 184 & 28,20 & 29,43 & 5.735 & $7.806 \mathrm{~b}$ \\
\hline Inoculação (I) & $\mathrm{p}<0,01$ & 0,712 & $\mathrm{p}<0,01$ & 0,384 & 0,861 & 0,104 & 0,147 & $\mathrm{p}<0,05$ \\
Doses (D) & 0,204 & $\mathrm{p}<0,01$ & 0,202 & $\mathrm{p}<0,01$ & 0,145 & $\mathrm{p}<0,01$ & $\mathrm{p}<0,05$ & $\mathrm{p}<0,01$ \\
I x D & 0,795 & 0,987 & 0,805 & 0,996 & 0,577 & 0,604 & 0,461 & 0,765 \\
\hline C.V. (\%) & 17,79 & 8,70 & 17,88 & 8,24 & 4,71 & 3,98 & 16,99 & 9,33 \\
\hline \hline
\end{tabular}

Médias seguidas pela mesma letra minúscula, na coluna, não diferem entre si, $($ Teste $F, P>0,05)$; C.V. $=$ coeficiente de variação. ${ }^{1} \mathrm{y}=$ $181,4+0,3 \mathrm{x}\left(\mathrm{R}^{2}=0,89\right) ;{ }^{2} \mathrm{y}=160,5+0,3 \mathrm{x}\left(\mathrm{R}^{2}=0,92\right) ;{ }^{3} \mathrm{y}=28,3957+0,0432 \mathrm{x}-0,0002 \mathrm{x}^{2}\left(\mathrm{R}^{2}=0,97\right) ;{ }^{4} \mathrm{y}=5318,40+10,90 \mathrm{x}\left(\mathrm{R}^{2}=0,65\right)$; ${ }^{5} \mathrm{y}=6902+20,1 \mathrm{x}\left(\mathrm{R}^{2}=0,85\right)$.

$=15,4434+0,0335 \mathrm{x})$, para o segundo ano não houve ajuste para doses de nitrogênio e tampouco diferença significativa para inoculação com $A$. brasilense (Tabela 2 e Figura 1). Por outro lado, os resultados obtidos por Kaneko et al. (2012), que avaliaram a inoculação com $A$. brasilense e doses de $\mathrm{N}$ em cobertura no milho na região de Chapadão do Sul - MS, foram negativos em relação à inoculação, de forma que os maiores valores para o teor de $\mathrm{N}$ nas folhas foram observados na ausência de inoculação. Deve-se observar que os teores de nitrogênio obtidos não se enquadram nos valores adequados segundo Malavolta (2006), onde constam valores de 28 - $35 \mathrm{~g} \mathrm{~kg}^{-1}$ de $\mathrm{N}$, contudo esses teores não influenciaram na produtividade.

De acordo com os resultados da população final de plantas por ha, verifica-se que houve diferença significativa para inoculação nos dois anos agrícolas, ou seja, a inoculação propiciou menor morte de plantas ao longo do ciclo (Tabela 2). O que pode ter ocorrido devido ao principal efeito da inoculação de sementes com A. brasilense, ou seja, a promoção do crescimento radicular das plantas fato relatado por Quadros et al. (2014), além disso, os mecanismos de tal efeito incluem ações diretas como a FBN, produção de re- 


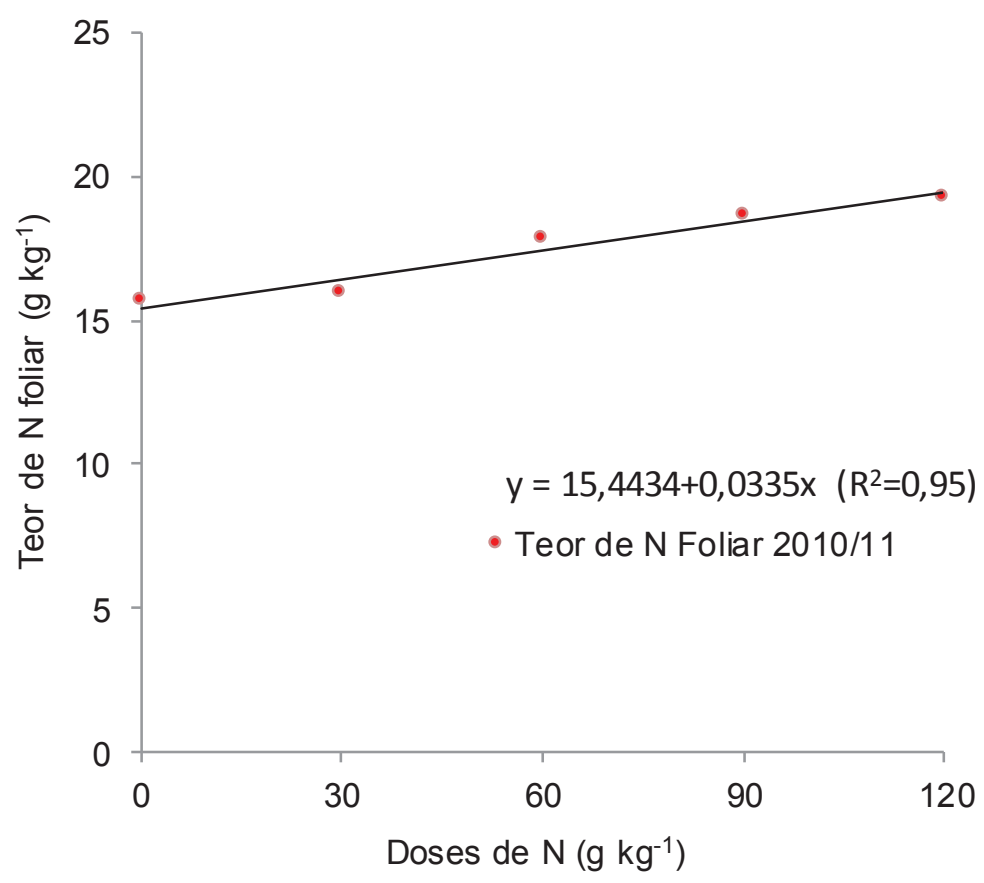

Figura 1. Teor de $\mathrm{N}$ foliar do milho no sistema plantio direto em função das doses de $\mathrm{N}$ em cobertura em 2010/11. Selvíria (MS), Brasil.

guladores de crescimento vegetal, solubilização de fosfato inorgânico. Dentre outros vários outros efeitos foram relatados, como incrementos na absorção da água e minerais, maior tolerância a estresses como salinidade e hídrico, resultando em uma planta mais vigorosa e produtiva (Xu et al., 2012).

No ano agrícola 2010/11 obteve-se 8.496 plantas ha-1 e em 2011/12 3.587 plantas ha $^{-1}$ em média a mais nos tratamentos em que houve inoculação com Azospirillum brasilense. Os dados obtidos por Portugal et al. (2012), avaliando a inoculação com $A$. brasilense via foliar associada à doses de nitrogênio em cobertura na cultura do milho em Selvíria - MS, confirmam o maior número final de plantas com a inoculação, divergindo dos dados encontrados por Kaneko et al. (2012), que obtiveram queda de 9,5\% na população nas áreas inoculadas em relação às não inoculadas, porem o autor relata que houve dificulda- de das sementes inoculadas com inoculante turfoso aderirem ao disco da semeadora a vácuo durante a operação de semeadura causando falha no momento da semeadura.

Houve diferença significativa $(\mathrm{p}<0,01)$ no primeiro ano (2010/11) para a massa total de espiga em relação à inoculação de $A$. brasilense, porém no segundo ano (2011/12) não houve tal diferença, como a redução da população de plantas tem-se um melhor desenvolvimento da espiga devido a menor competição intraespecífica o que pode ter interferido no resultado deste ano. Em 2011/12 pode-se observar ajuste à função linear crescente $(\mathrm{y}=0,1814+0,0003 \mathrm{x})$, portanto o aumento das doses de nitrogênio influenciou positivamente a massa total de espiga (Tabela 3 e Figura 2). Fato também relatado por Belusso et al. (2012) avaliando o comportamento de híbridos de milho com a variação das doses de nitrogênio em Sinop 
- MT, e os quais observaram aumento na massa total de espiga com o incremento da dose de nitrogênio.

A massa de grãos por espiga foi influenciada pela inoculação de sementes com Azospirillum brasilense no primeiro ano, o que não foi observado em 2011/12. As doses de nitrogênio em cobertura aumentaram a massa de grãos por espiga somente no segundo ano, de maneira linear crescente ( $y=160,515$ $+0,325 x$ ) (Tabela 3 e Figura 2). Também Carvalho et al. (2007), estudando espécies de cobertura de inverno e nitrogênio na cultura do milho em sistema de plantio direto em Castro - PR, observaram que o incremento da dose de nitrogênio aumentou a massa de grãos por espiga. Esse efeito positivo do $\mathrm{N}$ sobre o rendimento do milho já é bastante conhecido e reforça a importância do elemento para a cultura. Segundo Bredemeier \& Mundstock (2000), o N atua diretamente no desenvolvimento do milho, influenciando o rendimento da planta mais do que qualquer outro nutriente.
Foi observado efeito quadrático para a massa de 100 grãos nas diferentes doses de nitrogênio em cobertura $\left(y=28,3957+0,0432 x-0,0002 x^{2}\right)$ com ponto de máximo de 30,73 g para massa de 100 grãos para a dose de $108 \mathrm{~kg}$ de $\mathrm{N} \mathrm{ha}^{-1}$ (Tabela 3 e Figura 3). No ano 2010/11 pode-se verificar que não houve ajuste ( $\mathrm{p}>0,05)$, para as doses de N. Para a inoculação de sementes com $A$. brasilense não houve diferença significativa nos dois anos. Kaneko et al. (2012), também não observaram efeitos significativos para doses de $\mathrm{N}$ e para inoculação na massa de 100 grãos. Discordando de tais resultados Novakowiski et al. (2011), trabalhando com a cultura do milho em Guarapuava PR observaram que quando foi efetuada a inoculação por $A$. brasilense, a massa de mil grãos foi inferior quando comparada à adubação nitrogenada, contudo superior ao controle (sem fertilizante nitrogenado e sem inoculação de $A$. brasilense), o que indica que tais formas de manejo isoladas não apresentam bons resultados, porém a combinação das mesmas (ferti-

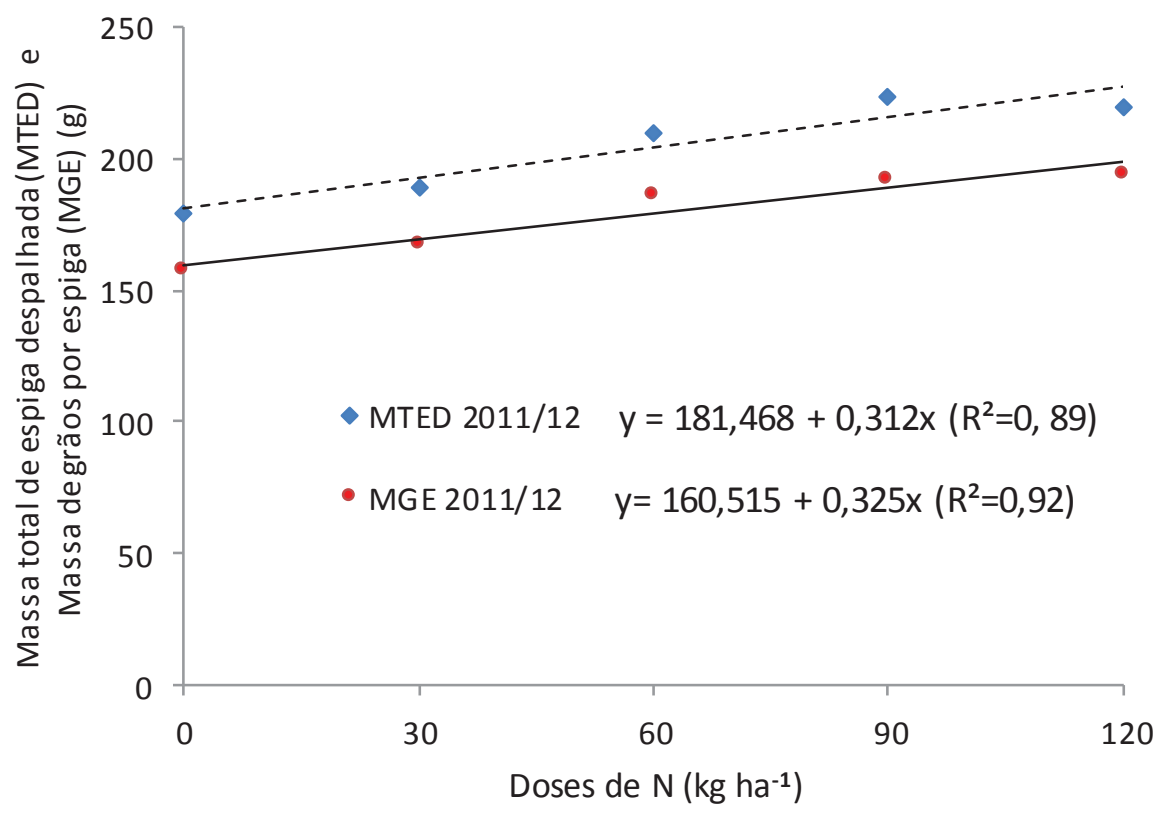

Figura 2. Massa total de espiga despalhada (MTED) e massa de grãos por espiga (MGE) do milho no sistema plantio direto em função das doses de N em cobertura em 2011/12. Selvíria (MS), Brasil. 
lizante nitrogenado + bactéria) pode reduzir a quantidade de insumos utilizada na cultura, elevando a massa de grãos e consecutivamente a produtividade da cultura. As doses de $\mathrm{N}$ em cobertura, em ambos os anos, influenciaram a produtividade de grãos com ajuste à função linear crescente $(\mathrm{y}=5318,4+10,9 \mathrm{x}$ e $y=6902,1+20,1 x)$, ou seja, houve aumento da produtividade com o aumento das doses de nitrogênio (Tabela 3 e Figura 4). Para inoculação de sementes com Azospirillum brasilense em 2011/12 foi observado aumento de produtividade com a inoculação de sementes, tendo incremento na produtividade de 0,61 $\mathrm{Mg} \mathrm{ha}^{-1}$. Em 2010/11 não houve diferença significativa para inoculação embora numericamente os valores sejam maiores. É interessante destacar que nos dois anos de cultivo a inoculação das sementes com Azospirillum brasilense proporcionou maior população de plantas o que deve ter contri- buído para aumentar a produtividade de grãos no tratamento com inoculação das sementes. Godoy et al. (2011), estudando a produtividade de milho em resposta a doses de nitrogênio com e sem inoculação das sementes com Azospirillum brasilense em Campo Mourão - PR, observaram aumento de produtividade resultante do aumento das doses de $\mathrm{N}$, por outro lado para a inoculação não obtiveram aumento da produtividade. Resultados semelhantes foram obtidos por Carreira et al. (2012), que avaliaram o efeito da inoculação de sementes com Azospirillum brasilense na produtividade de milho no Sudoeste Goiano. Porém, Basi (2013) estudando a adubação nitrogenada e inoculação com $A$. brasilense em híbridos de milho em Iraí de Minas - MG observou que a inoculação com Azospirillum brasilense e o incremento das doses de nitrogênio promoveram aumento médio na produtividade de grãos.

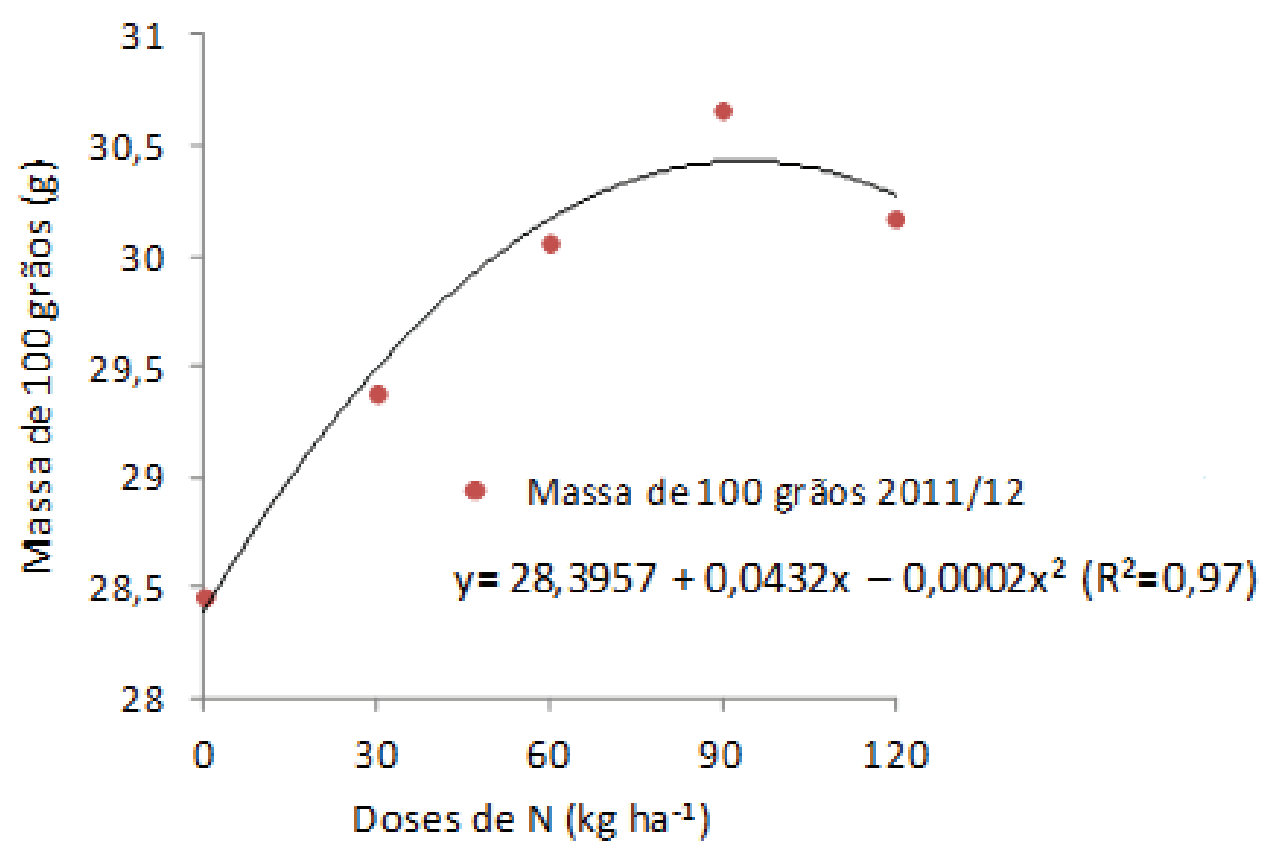

Figura 3. Massa de 100 grãos do milho no sistema plantio direto em função das doses de $\mathrm{N}$ em cobertura em 2011/12. Selvíria (MS), Brasil. 


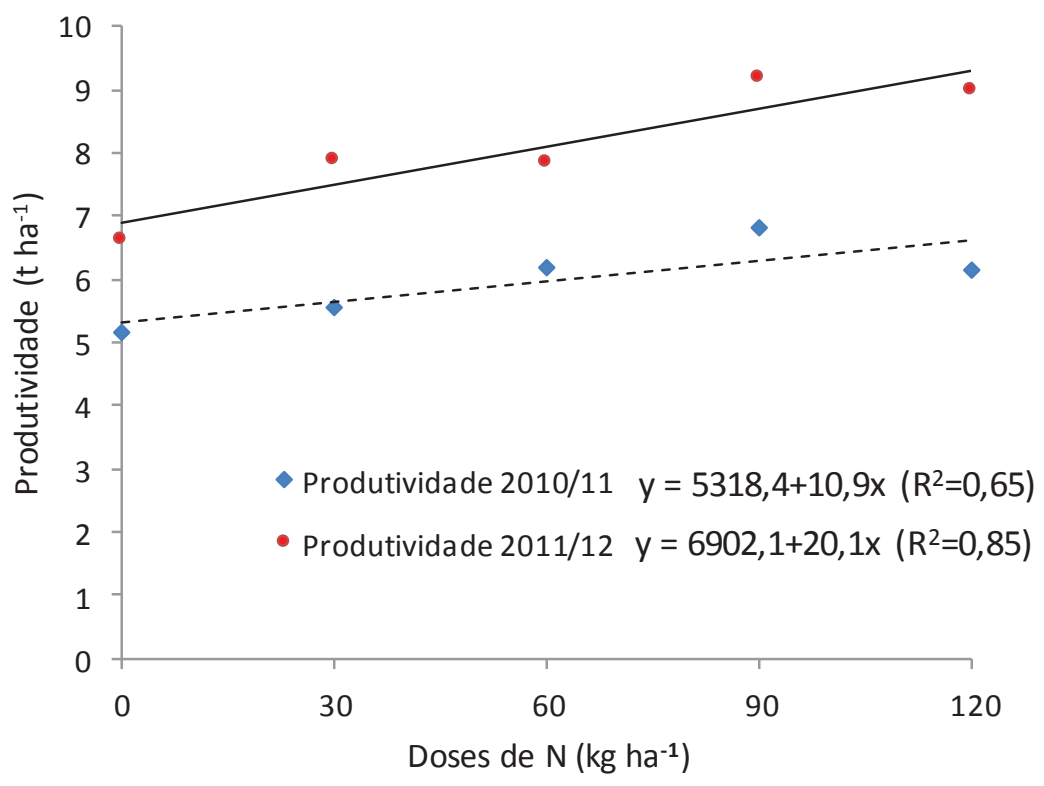

Figura 4. Produtividade do milho no sistema plantio direto em função das doses de $\mathrm{N}$ em cobertura em 2010/11 e 2011/12. Selvíria (MS), Brasil.

Não houve interação entre inoculação e as doses de nitrogênio para nenhuma das variáveis avaliadas, demonstrando que estes fatores se comportam de forma independente. Da mesma forma, Repke et al. (2013) avaliando o efeito do nitrogênio e da inoculação de sementes com Azospirillum brasilense na produtividade de grãos de milho não observaram interação entre as doses de nitrogênio e a inoculação de sementes com Azospirillum brasilense.

Estes resultados podem ser explicados pela maior absorção e acúmulo de nutrientes nos grãos de milho, Isto se deve a capacidade desta bactéria ser diazotrófica (fixação biológica de N2), e principalmente pela capacidade do Azospirillum brasilense em sintetizar hormônios que contribuem no crescimento dos tecidos das plantas, principalmente do sistema radicular, o qual mais vigoroso possibilita maior absorção de água e nutrientes, assim como maior redistribuição de nutrientes e fotoassimilados para espiga.

\section{Conclusões}

- A inoculação de sementes de milho com Azospirillum brasilense proporcionou maior população final de plantas, massa total de espiga despalhada, massa de grãos por espiga e produtividade de grãos.

- O incremento das doses de nitrogênio aplicado em cobertura aumentou o teor de $\mathrm{N}$ foliar, a massa de 100 grãos e a produtividade de grãos.

- Recomenda-se a aplicação de $120 \mathrm{~kg} \mathrm{ha}^{-1}$, com a inoculação, pois foi o tratamento mais produtivo.

\section{Referências}

ACOMPANHAMENTO DA SAFRA BRASILEIRA [DE] GRÃOS: safra 2018/19: quinto levantamento. Brasília, DF: Conab, v. 6, n. 5, fev. 2019. 
BASHAN, Y.; DE-BASHAN, L. E. How the plant growthpromoting bacteria Azospirillum promotes plant growth: a critical assessment. Advances in Agronomy, San Diego, v. 108 , n. 1, p. 77-136, 2010.

DOI: 10.1016/S0065-2113(10)08002-8.

BASI, S. Associação de Azospirillum brasilense de nitrogênio em cobertura na cultura do milho. 2013. 50 f. Dissertação (Mestrado em Agronomia) - Universidade Estadual do Centro-Oeste, Guarapuava, 2013.

BELUSSO, L.; BOTELHO, F. B. S.; ARANTES, S. N. A. C. M.; DIEL, D.; BONETTI, J. A.; BOTIN, A. A.; ARANTES, K. R. Comportamento de híbridos de milho frente às variações de nitrogênio no solo. Revista de Ciências Agro-Ambientais, Alta Floresta- MT, v. 10, n. 1, p. 33-41, 2012.

BERGAMASCHI, C. Ocorrência de bactérias diazotróficas associadas às raízes e colmos de cultivares de sorgo. 2006. 71 f. Dissertação (Mestrado em Microbiologia Agrícola) - Universidade Federal do Rio Grande do Sul, Porto Alegre, 2006.

BRASIL. Ministério da Agricultura, Pecuária e Abastecimento. Brasília, DF, 2012. Homepage. Disponível em: <http://www.agricultura.gov.br>. Acesso em: 25 fev. 2012.

BREDEMEIER, C.; MUNDSTOCK, C. M. Regulação da absorção e assimilação do nitrogênio nas plantas. Ciência Rural, Santa Maria, v. 30, n. 2, p. 365-372, 2000. DOI: $10.1590 / \mathrm{S} 0103-84782000000200029$.

CARREIRA, F. da S.; FURTADO, N. da S.; BASTOS, F. J.; CUNHA F. N.; ROCHA, A. C.; SOUCHIE, E. L. Efeito da Azospirillum brasilense na produtividade de milho no sudoeste goiano. In: CONGRESSO DE PESQUISA E PÓS-GRADUAÇÃO DO CAMPUS RIO VERDE, 1., 2012, Rio Verde. Anais... Rio Verde: Instituto Federal Goiano, 2012.

CARVALHO, I. Q.; SILVA, M. J. S.; PISSAIA, A.; PAULETTI, V.; POSSAMA, J. P.; Espécies de cobertura de inverno e nitrogênio na cultura do milho em sistema de plantio direto. Scientia Agraria, Piracicaba, v. 8, n. 2, p. 179-184, 2007. DOI: 10.5380/rsa.v8i2.8367.

CENTURION, J. F. Balanço hídrico da região de Ilha Solteira. Científica, São Paulo, v. 10, n. 1, p. 57-61, 1982.

CRUZ, J. C. (Ed.). Cultivo do milho. 8. ed. Sete Lagoas: Embrapa Milho e Sorgo, 2012. (Embrapa Milho e Sorgo. Sistema de Produção, 1). Disponível em: <http://www. cnpms.embrapa.br/publicacoes/milho_8_ed/index.htm>. Acesso em: 13 abr. 2013.

FERREIRA, D. F.; SISVAR: a computer statistical analysis system. Ciência e Agrotecnologia, Lavras, v. 35, n. 6, p. 1039-1042, nov./dez. 2011.

DOI: 10.1590/S1413-70542011000600001.

FRANCISCO, E. A. B.; KAPPES, C.; DOMINGUES, L.; FELIPPI, C. L. Inoculação de sementes de milho com Azospirillumbrasilenseeaplicaçãodenitrogênioemcobertura. In: CONGRESSO NACIONAL DE MILHO E SORGO, 29., Águas de Lindóia, 2012. Anais... Águas de Lindóia: Associação Brasileira de Milho e Sorgo, 2012.p. 1285-1291.

GODOY, J. C. S.; FIORI, C. C. L.; WATANABE, S. H.; GUARIDO, R. C. Produtividade de milho em resposta a doses de nitrogênio com e sem inoculação das sementes com Azospirillum brasilense. Campo Digit@1, v. 6, n. 1, p. 26-30, 2011.

KANEKO, F. H.; ARF, O.; LEAL, A. J. F.; PIATI, G. L.; GORGEN, B. R.; BUZETTI, S.; ARF, M. V.; FRANZOTE, F. H. Inoculação com Azospirillum brasilense, ureia e ureia revestida com polímero e doses de $\mathrm{N}$ em cobertura no milho cultivado em cerrado de maior altitude. In: CONGRESSO NACIONAL DE MILHO E SORGO, 29., Águas de Lindóia, 2012. Anais... Águas de Lindóia: Associação Brasileira de Milho e Sorgo, 2012. p. 1299-1305.

MALAVOLTA, E. Manual de nutrição mineral de plantas. Piracicaba: Ceres, 2006. 631 p.

MALAVOLTA, E.; VITTI, G. C.; OLIVEIRA, S. A. Avaliação do estado nutricional das plantas: princípios e aplicações. 2. ed. Piracicaba: Potafos, 1997. 201 p. 
NOVAKOWISKI, J. H.; SANDINI, I. E.; FALBO, M. K.; MORAES, A. de; NOVAKOWISKI, J. H.; CHENG, N. C. Efeito residual da adubação nitrogenada e inoculação de Azospirillum brasilense na cultura do milho. Semina: Ciências Agrárias, Londrina, v. 32, n. 4, p. 1687-1698, 2011. Suplemento.

DOI: 10.5433/1679-0359.2011v32n4Sup1p1687.

PORTUGAL, J. R.; ARF, O.; LONGUI, W. V.; GITTI, D. C.; BARBIERI, M. K. F.; GONZAGA, A. R.; TEIXEIRA, D. S. Inoculação com Azospirillum brasilense via foliar associada à doses de nitrogênio em cobertura na cultura do milho. In: CONGRESSO NACIONAL DE MILHO E SORGO, 29., Águas de Lindóia, 2012. Anais... Águas de Lindóia: Associação Brasileira de Milho e Sorgo, 2012. p. 1413-1419.

QUADROS, P. D.; ROESCH, L. F. W.; SILVA, P. R. F.; VIEIRA, V. M.; ROEHRS, D. D.; CAMARGO, F. A. O. Desempenho agronômico a campo de híbridos de milho inoculados com Azospirillum. Revista Ceres, Viçosa, $\mathrm{MG}$, v. 61, n. 2 , p. $209-218,2014$

DOI: $10.1590 / \mathrm{S} 0034-737 \mathrm{X} 2014000200008$.

RAIJ, B. van; ANDRADE, J. C.; CANTARELLA, H.; QUAGGIO, J. A. Análise química para avaliação da fertilidade de solos tropicais. Campinas: Instituto Agronômico, 2001. 285 p. (IAC. Boletim, 100).

REPKE, R.A.; CRUZ, S. J. S.; SILVA, C. J.; FIGUEIREDO, P. G.; BICUDO, S. J. Eficiência do Azospirillum brasilense combinada com doses de nitrogênio no desenvolvimento de plantas de milho. Revista Brasileira de Milho e Sorgo, Sete Lagoas, v. 12, n. 3, p. 214-226, 2013. DOI: 10.18512/1980-6477/rbms.v12n3p214-226.

REIS, V. M.; BALDANI, V. L. D.; BALDANI, J. I.; DÖBEREINER, J. Biological nitrogen fixation in gramineae and palm trees. Critical Review in Plant Sciences, v. 19, $\mathrm{n}$. 3, p. 227-247, 2000. DOI: 10.1080/07352680091139213.

SANGOI, L. Understanding plant density effects on maize growth and development: an important issue to maximize grain yield. Ciência Rural, Santa Maria, v. 31, n. 1, p. 159168, 2001. DOI: 10.1590/S0103-84782001000100027.

SANTOS, H. G. dos; JACOMINE, P. K. T.; ANJOS, L. H. C. dos; OLIVEIRA, V. A. de; LUMBRERAS, J. F.; COELHO, M. R.; ALMEIDA, J. A. de; CUNHA, T. J. F.; OLIVEIRA, J. B. de. Sistema brasileiro de classificação de solos. 3. ed. rev. e ampl. Brasília, DF: Embrapa, 2013. 353 p.

SILVA, M. A. G.; PORTO, S. M. A.; MANNIGEL, A. R.; MUNIZ, A. S.; MATA, J. D. V.; NUMOTO, A. Y. Manejo da adubação nitrogenada e influência no crescimento da aveia preta e na produtividade do milho em plantio direto. Acta Scientiarum. Agronomy, Maringá, v. 31, n. 2, p. 275-281, 2009.

SIlVA, A. G. D.; DUARTE, A. P.; PIEDADE, R. D. C.; COSTA, H. P.; MEIRELES, K. G. C.; BORGES, L. P. Inoculação de sementes de milho safrinha com Azospirillum e aplicação de nitrogênio em cobertura. Revista Brasileira de Milho e Sorgo, Sete Lagoas, v. 14, n. 3, p. 358-370, 2016. DOI: 10.18512/1980-6477/rbms.v14n3p358-370.

WEBER, M. A.; MIELNICZUK, J. Estoque e disponibilidade de nitrogênio no solo em experimento de longa duração. Revista Brasileira de Ciência do Solo, Viçosa, MG, v. 33, n. 2, p. 429-437, 2009.

DOI: 10.1590/S0100-06832009000200020.

XU, G.; FAN, X.; MILLER, A. J. Plant nitrogen assimilation and use efficiency. Annual Review of Plant Biology, Palo Alto, v. 63, n. 5, p. 153-182, 2012.

DOI: 10.1146/annurev-arplant-042811-105532. 